\title{
FURTHER INVESTIGATIONS ON POTASSIUM-INDUCED AUTOMATICITY OF ISOLATED HUMAN RENAL ARTERY
}

\author{
Shoichi UEDA*, Keiichi IKEGAMI*, Ken-ichi YONEMURA** \\ and Matao SAKANASHI \\ Department of "Urology, " Physiology and Pharmacology. \\ Kumamoto University Medical School. Kumamoto 860. Japan
}

Accepted April 29, 1981

\begin{abstract}
Experiments were designed to investigate generation of automaticity of isolated human renal arteries induced by administration of potassium in vitro. Helical strips of human renal arteries showed marked oscillations in the potassium-induced contractions which persisted for $2 \mathrm{hr}$. Indomethacin and aspirin dose-dependently inhibited these oscillations. Tranylcypromine and mepacrine also had an inhibitory action on the oscillations of the strips induced by potassium. In the strips which reached a steady state $2 \mathrm{hr}$ after administration of potassium, phospholipase $A_{2}$ and bradykinin produced marked oscillations. Our results indicate that human renal arteries can generate automaticity in the contractions induced by potassium, and that such automaticity may be related to the biosynthesis of prostaglandins.
\end{abstract}

In a preliminary report (1), we showed that the isolated human renal arteries produced marked oscillations in the contractions in response to potassium, and the plausibility that generation of such automaticity might be related to prostaglandin biosynthesis, particularly vasodilating prostaglandins, was discussed. In the present study, we attempted to confirm the hypothesis and to elucidate the possible contribution of endogenous prostaglandins to generation of automaticity in human renal arteries.

\section{MATERIALS AND METHODS}

Preparations of human renal arteries were obtained from ten patients who underwent nephrectomy for tumors of the kidney $(63$ and 57 year old women, and 63 and 49 year old men) and ureters ( 69 and 52 year old men) and for renal calculus $(59$ and 41 year old women, and 43 and 28 year old men). Experimental procedures were the same as reported previously (1). Helical strips, 2.0 $\mathrm{mm}$ wide and $20 \mathrm{~mm}$ long, cut from a small branch $(1.5-2.0 \mathrm{~mm}$ in diameter) of the renal arteries were suspended in a $20-\mathrm{ml}$ muscle bath filled with Krebs-Ringer bicarbonate solution of the following composition ( $\mathrm{mM}$ ): $\mathrm{NaCl}$ 117.7. $\mathrm{KCl} 4.7, \mathrm{CaCl}_{2} 2.5, \mathrm{MgSO}_{4} 1.2$, $\mathrm{KH}_{2} \mathrm{PO}_{4}$ 1.2. $\mathrm{NaHCO}_{3} 24.4$ and glucose 10.0. The solution was maintained at $37^{\circ} \mathrm{C}$ and aerated with a gas mixture of $95 \% \mathrm{O}_{2}$ and $5 \% \mathrm{CO}_{2}$. The oxygen tension of the solution was $600 \mathrm{mmHg}$ and the $\mathrm{pH}$ was 7.40 when measured by a blood gas analyzer (Instrumentation Laboratory Micro-13). Under an initial or passive tension of $1.0 \mathrm{~g}$, isometric tension developments of the strips were recorded on an ink-writing recticorder (Nihon Kohden RJG-4004) through a forcedisplacement transducer (Nihon Kohden TB- 
611T). The renal arterial strips were allowed to equilibrate for $2 \mathrm{hr}$ before each experiment.

The following drugs were used: indomethacin (Sigma), aspirin (Sigma), phospholipase $A_{2}$ (Sigma), bradykinin (Sigma), tranylcypromine hydrochloride (Sigma) and mepacrine dihydrochloride (Sigma). Indomethacin and aspirin were dissolved in ethanol including sodium bicarbonate equimolar to indomethacin or aspirin, and diluted with physiological saline. Other drugs were dissoived in physiological saline. All solvents had no effect. Drug solutions were added to the bath in a volume of $0.2 \mathrm{ml}$. The final concentrations of the salts in tranylcypromine and mepacrine and of free forms in indomethacin, aspirin, phospholipase $A_{2}$ and bradykinin were expressed in terms of $\mathrm{g} /$ $\mathrm{ml}$, except for potassium

\section{RESULTS}

Administration of potassium $15 \mathrm{mM}$ produced rapid contractions of the human renal arterial strips $(n=8)$ followed by marked oscillations with a tension from $150 \mathrm{mg}$ to $1000 \mathrm{mg}$ occurring at a rate of 3-5 times/10 min (Figs, 1-3). Marked oscillations in the tension were observed to persist for $2 \mathrm{hr}$, and thereafter the strips reached a steady state with the same small oscillations from $25 \mathrm{mg}$ to $50 \mathrm{mg}$ observed in control conditions (Fig. 3), In 4 pre- parations with marked oscillations in the tension following administration of potassium $15 \mathrm{mM}$, indomethacin $3 \times 10^{-7} \mathrm{~g} / \mathrm{ml}$, applied $15 \mathrm{~min}$ after potassium, did not change the oscillations although it did elevate the basal tension of the strips $(250-500 \mathrm{mg})$. Indomethacin $3 \times 10^{-6} \mathrm{~g} / \mathrm{ml}$, cumulatively applied $20 \mathrm{~min}$ after the first application of indomethacin, decreased the vascular tone but had little effect on oscillations in the tension. However, when a higher dose $\left(3 \times 10^{-5} \mathrm{~g} / \mathrm{ml}\right)$ of indomethacin was cumulatively applied $20 \mathrm{~min}$ after the second application of indomethacin, marked oscillations disappeared with a decline of the vascular tone (Fig. 1 upper trace). Aspirin $10^{-5}-10^{-4} \mathrm{~g} / \mathrm{ml}$ dose-dependently inhibited the oscillations $(n=4)$ induced by potassium in the same manner as indomethacin (Fig. 1 lower trace). In these strips, however, the vascular tone was gradually decreased by cumulative doses of aspirin.

Tranylcypromine $10^{-5} \mathrm{~g} / \mathrm{ml}$ further increased the tension (250-500 $\mathrm{mg}$ ) of the strips $(n=4)$ showing marked oscillations in the contractions by potassium $15 \mathrm{mM}$, and did not produce significant alterations of the oscillations. Tranylcypromine $10^{-4} \mathrm{~g} / \mathrm{ml}$ significantly increased the vascular tone (about $1,000 \mathrm{mg}$ ) and eliminated the potassium-induced oscillations (Fig. 2 upper trace). Mepacrine $10^{-6} \mathrm{~g} / \mathrm{ml}$ enhanced the

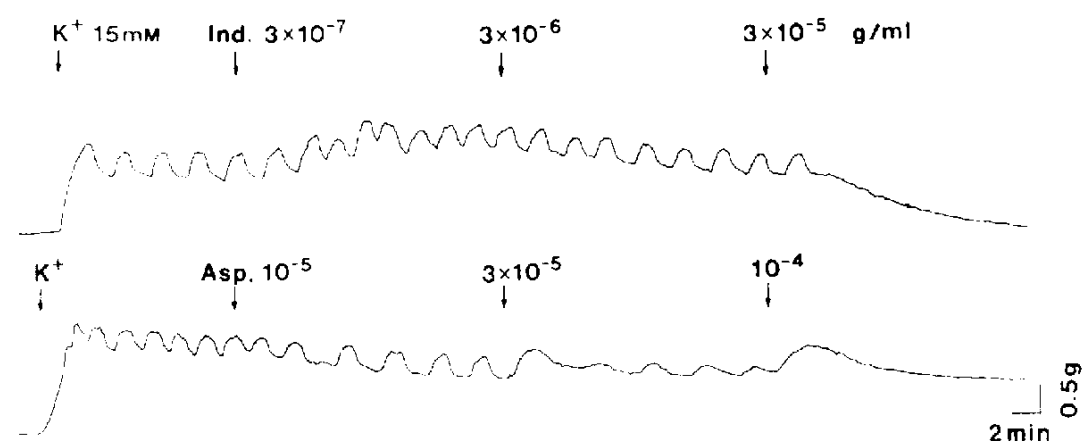

Fig. 1. Effects of indomethacin (Ind.) and aspirin (Asp.) on potassium ( $\left.\mathrm{K}^{+}\right) 15 \mathrm{mM}$-induced oscillations in the contractions of isolated human renal arterial strips. 


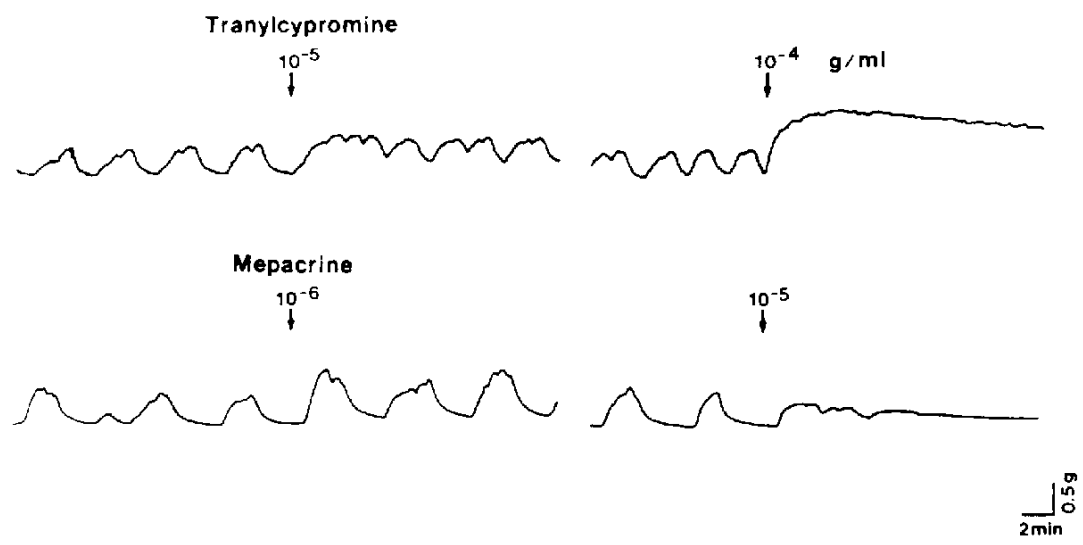

Fig. 2. Effects of tranylcypromine and mepacrine on potassium $15 \mathrm{mM}$-induced oscillations in the contractions of isolated human renal arterial strips. The interval between the left and the right panel in each recording is $30 \mathrm{~min}$.

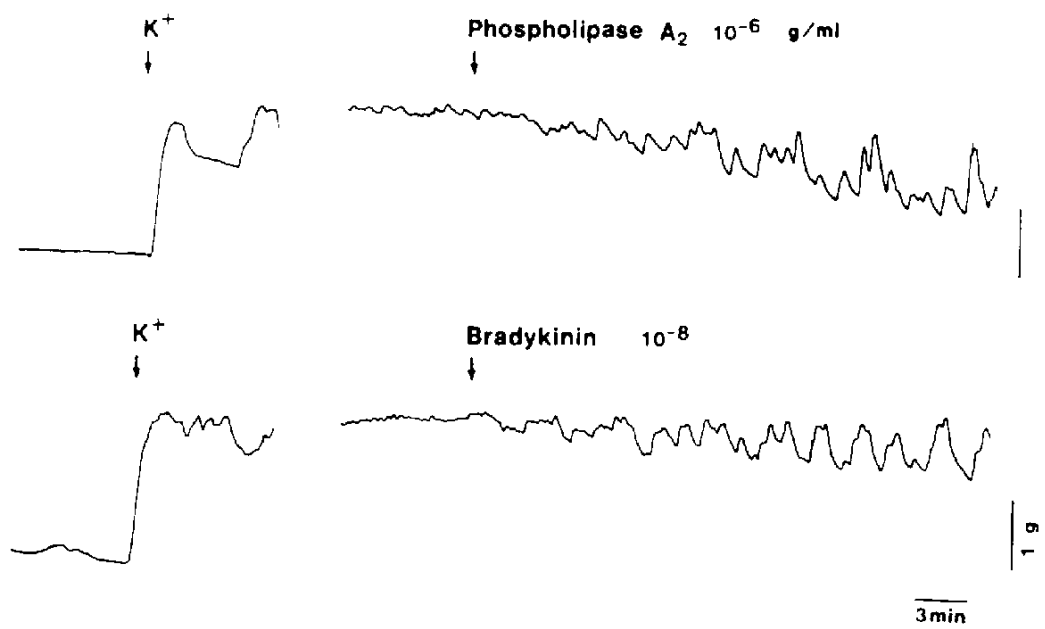

Fig. 3. Effects of phospholipase $A_{2}$ and bradykinin on isolated human renal arterial strips which reached a steady state $2 \mathrm{hr}$ after administration of potassium $\left(\mathrm{K}^{+}\right) 15 \mathrm{mM}$. The interval between the left and the right panel in each recording is $2 \mathrm{hr}$.

amplitude of the oscillations (1,000-1,250 $\mathrm{mg}$ ) of the renal arterial strips $(n=4)$ without altering the frequency of the oscillations and the vascular tone. The effect of the drug persisted for about $30 \mathrm{~min}$. Mepacrine $10^{-5}$ $\mathrm{g} / \mathrm{ml}$ resulted in a disappearance of marked oscillations in the tension $10 \mathrm{~min}$ after application of the drug (Fig. 2 lower trace).

In the strips which reached a steady state $2 \mathrm{hr}$ after administration of potassium $15 \mathrm{mM}$. an addition of phospholipase $A_{2} 10^{-6} \mathrm{~g} / \mathrm{ml}$ $(n=4)$ or bradykinin $10^{-8} \mathrm{~g} / \mathrm{ml} \quad(n=4)$ produced marked oscillations in the tension along with the decline of the vascular tone (Fig. 3). These oscillations were not observed when indomethacin $3 \times 10^{-5} \mathrm{~g} / \mathrm{ml}$ was applied 10 min prior to administration of phospholipase $\mathrm{A}_{2}$ or bradykinin.

\section{DISCUSSION}

Confirming the observations in a preliminary study (1), the present study 
showed that marked oscillations in the tension of the isolated human renal arterial strips induced by potassium could be diminished by indomethacin or aspirin. Since anti-inflammatory agents such as indomethacin or aspirin inhibit the activity of cyclooxygenase (prostaglandin endoperoxide synthetase) (2, 3), diminution of marked oscillations by these drugs may be related to inhibition of endogenous prostaglandin production. Though the present data does not rule out the possibility that indomethacin or aspirin, in high doses, may inhibit the potassium-induced oscillations in the tension of the arteries through non-specific inhibitory actions on vascular smooth muscles, the inhibition of marked oscillations by mepacrine further suggests the participation of endogenous prostaglandin biosynthesis in generation of the oscillations. Indeed, mepacrine is reported to inactivate phospholipase $A_{2}$ which releases arachidonic acid from phospholipids (4-6). Judging from the result that tranylcypromine, an inhibitor of prostacyclin biosynthesis (7, 8), abolished marked oscillations in the tension of the human renal arterial strips, generation of marked oscillations by potassium may be due to production of prostacyclin. Potassiumincreased tension developments of the strips may activate biosynthesis of prostacyclin which transiently relaxes the strips because of its short activity, resulting in generation of the oscillations. In fact, generation of prostacyclin in the human colic or gastric arteries has been confirmed in biochemical studies (9). Thus, indomethacin, aspirin, mepacrine or tranylcypromine may induce inhibitory effects on marked oscillations in the tension of the isolated human renal arteries, through inhibition of endogenous prostaglandin biosynthesis.

To determine whether or not marked oscillations in the tension of the human renal arterial strips could be evoked by stimulation of endogenous prostaglandin biosynthesis, the effects of two activators of prostaglandin biosynthesis, phospholipase $A_{2}$ and bradykinin, were investigated on the strips which reached a steady state $2 \mathrm{hr}$ after administration of potassium. Phospholipase $A_{2}$ can activate the prostaglandin biosynthesis through metabolism of arachidonic acid (4-6). Bradykinin has been observed to release prostaglandin-like substances from renal, mesenteric or coetiac vasculature (1012). and to stimulate the phospholipase $A_{2}$ activity (4). Bradykinin also can activate the prostaglandin biosynthesis. We have shown that both phospholipase $A_{2}$ and bradykinin can evoke marked oscillations in the tension of the human renal arterial strips, under conditions of a steady state. These findings may further support the view of the participation of endogenous prostaglandin biosynthesis in generation of such oscillations.

Considering that marked oscillations in the tension of the renal arterial strips followed a rapid contraction by administration of potassium, the possibility that occurrance of the oscillations may be related to enhancement of endogenous prostaglandin biosynthesis, due to mechanical changes in vascular smooth muscles, warrants further investigation.

\section{REFERENCES}

1) Ueda, S., Ikegami, K., Yonemura, K. and Sakanashi, M.: Potassium-induced automaticity of isolated human renal artery. Japan. J. Pharmacol. 31, 134-136 (1981)

2) Di Rosa, M., Papadimitriou, J.M. and Willoughby, D.A.: A histopathological and pharmacological analysis of the mode of action of non-steroidal anti-inflammatory drugs. J. Pathol. 105, 239-256 (1971)

3) Flower, R.J.: Drugs which inhibit prostaglandin biosynthesis. Pharmacol. Rev. 26, 33-67 (1974)

4) Vargaftig, B.B. and Dao Hai, N.: Selective inhibition by mepacrine of the release of "rabbit aorta contracting substance" evoked by the administration of bradykinin. J. Pharm. 
Pharmacol. 24, 159-161 (1972)

5) Flower, R.J. and Blackwell, G.J.: The importance of phospholipase $A_{2}$ in prostaglandin biosynthesis. Biochem. Pharmacol. 25, 285291 (1976)

6) Blackwell, G.J., Duncombe, W.G., Flower, R.J., Parsons, M.F. and Vane, J.R.: The distribution and metabolism of arachidonic acid in rabbit platelets during aggregation and its modification by drugs. Brit. J. Pharmacol. 59, 353-366 (1977)

7) Gryglewski, R.J., Bunting, S., Moncada, S., Flower, R.J. and Vane, J.R.: Arterial walls are protected against deposition of platelet thrombi by a substance (prostaglandin $X$ ) which they make from prostaglandin endoperoxides. Prostaglandins 12,685-713 (1976)

8) Bunting, S., Gryglewski, R.J., Moncada, S. and Vane, J.R.: Arterial walls generate from prostaglandin endoperoxides a substance (prostaglandin $X$ ) which relaxes strips of mesenteric and coeliac arteries and inhibits platelet aggregation. Prostaglandins 12, 897913 (1976)

9) Moncada, S., Higgs, E.A. and Vane, J.R. Human arterial and venous tissues generate prostacyclin (prostaglandin $X$ ), a potent inhibitor of platelet aggregation. Lancet $i, 18-21$ (1977)

10) McGiff, J.C., Terragno, N.A., Malik, K.U. and Lonigro, A.J.: Release of a prostaglandin Elike substance from canine kidney by bradykinin. Circulation Res. 31, 36-43 (1972)

11) Terragno, D.A., Crowshaw, K., Terragno, N.A. and McGiff, J.C.: Prostaglandin synthesis by bovine mesenteric arteries and veins. Circulation Res. Supp. I, 36, 37, 1-76-80 (1975)

12) Colina-Chourio, J., McGiff, J.C., Miller, M.P. and Nesjletti, A.: Possible influence of intrarenal generation of kinins on prostaglandin release from the rabbit perfused kidney. Brit. J, Pharmacol. 58, 165-172 (1976) 